\title{
Minimum current requirement for confirming the localization of an epiradicular catheter placement
}

\author{
Ji Seon Jeong, Jae Chol Shim, Jae Hang Shim, Dong Won Kim, and Min Serk Kang \\ Department of Anesthesiology and Pain Medicine, School of Medicine, Hanyang University, Seoul, Korea
}

Background: Based on the necessity to confirm the epiradicular catheter misplacement, epiradicular threshold current for the confirmation of catheter tip localization is required.

Methods: Thirty-four adult patients with low extremity radiating pain were to receive epiradicular catheterization at the lumbosacral level. The epidural space was accessed percutaneously in cranial to caudal direction. A metal coil-reinforced epidural catheter was inserted and advanced caudolaterally toward the target neural foramen until the catheter tip was located below the bisection of pedicle. The electrical stimulation was performed after catheter placement in epidural and epiradicular space. Using the constant current nerve stimulator, the stimulating current was increased from 0 to $5 \mathrm{~mA}$ (pulse width of $0.3 \mathrm{~ms}$; frequency of $2 \mathrm{~Hz}$ ) until adequate motor contraction was evident. The threshold current for motor response with epidural space (EDmA) and epiradicular space (ERmA) placement were recorded upon electrical stimulation. In addition, the threshold charge for motor response with epidural (EDnC) and epiradicular (ERnC) placement were recorded.

Results: Of 34 catheters intentionally placed in the epiradicular space, ERmA was $0.53 \pm 0.48 \mathrm{~mA}$. The ERnC was significantly lower than EDnC $(\mathrm{P}<0.05)$. The EDmA and ERmA were below $1 \mathrm{~mA}$ in 3 patients and above $1 \mathrm{~mA}$ in 4 patients, respectively.

Conclusions: We conclude that, threshold current for motor response seems to be lower for epiradicular compared with epidural placement, although we were not able to directly investigate the epidural threshold current. The threshold current of epiradicular space overlap that in the epidural space. (Korean J Anesthesiol 2012; 63: 238-244)

Key Words: Epidural, Epidural stimulation, Epiradicular, Threshold current.

Received: February 22, 2012. Revised: March 14, 2012. Accepted: April 16, 2012.

Corresponding author: Jae Chol Shim, M.D., Ph.D., Department of Anesthesiology and Pain Medicine, School of Medicine, Hanyang University, 17, Haengdang-dong, Seongdong-gu, Seoul 133-070, Korea. Tel: 82-2-2290-8680, Fax: 82-2-2299-8692, E-mail: jcshim@hanyang.ac.kr (c) This is an open-access article distributed under the terms of the Creative Commons Attribution Non-Commercial License (http:// creativecommons.org/licenses/by-nc/3.0/), which permits unrestricted non-commercial use, distribution, and reproduction in any medium, provided the original work is properly cited. 


\section{Introduction}

Epidural analgesia is an effective analgesic technique for postoperative pain control and pain therapy [1-4]; however the primary failure rate of epidural space catheterization can exceed $10 \%$ [5]. Moreover, epidural catheter tips located in the transforaminal passage were demonstrated by epidurography in 3 of the 236 consecutive epidural anesthesia patients [6] and cases of spinal cord injury or intracord injection during attempted epidural anesthesia under general anesthesia have occurred $[7,8]$. As a result, there is considerable apprehension about performing central neuraxial blockade in anesthetized or heavily sedated patients because of the potential for neurological complications [9]. Therefore, a reliable real time, simple, safe, and objective technique to confirm epidural catheter placement is needed. The electrical stimulation test (EST), as described a decade ago by Tsui et al. [10], could be a useful tool to confirm the correct location of an epidural catheter by the minimum milliamperage $(\mathrm{mA})$ required for an appropriate muscle contraction.

The EST criteria define correct localization of the catheter tip in the epidural space by elicited motor response with a current between $1-10 \mathrm{~mA}$ at a frequency of $1 \mathrm{~Hz}$ with a pulse width of $0.2 \mathrm{~ms}[10,11]$. The EST criteria are based on the assertion that "when a catheter is situated properly within the epidural space, muscle twitches are typically elicited with a current much greater than $1 \mathrm{~mA}$." Any motor response observed at $<1 \mathrm{~mA}$ is considered a warning sign for possible subdural, subarachnoid, or epiradicular (nerve root adjacency) catheter position.

In regard to the lower limit $1 \mathrm{~mA}$, it was established that any motor response observed at $<1 \mathrm{~mA}$ or barely above $1 \mathrm{~mA}$ might suggest catheter placement in the subarachnoid, subdural or in close proximity to a nerve root, [11-14] although not an absolute limit. However, segmental motor responses at $<1 \mathrm{~mA}$ or equal to $1 \mathrm{~mA}$ were encountered with epidural catheter position $[11,15,16]$. Furthermore, of the 11 catheters intentionally placed in the intrathecal space, the mean current required to produce an appropriate palpable motor contraction was $1.3 \pm 0.8 \mathrm{~mA}$ with a range of 0.05 to $2.4 \mathrm{~mA}$. These data are not in accordance with the Tsui's concept [11].

The unilateral epidural block due to misplacement of epidural catheter was reported and the cause might be due to the epidural catheter tip being located in the anterior epidural space or in the paravertebral area (nerve-root adjacency) [6]. This reflects the necessity of EST to confirm the epiradicular (nerve-root adjacency) catheter misplacement based on the data of epiradicular threshold current. However, to the best of author's knowledge, epiradicular threshold current for the confirmation of catheter tip localization has never been investigated in a formal observational study except for only one case report [14].

This investigation evaluated (a) the threshold current for epiradicular catheter placement; (b) the hypothesis that the threshold current required to elicit a motor response in the epiradicular space is lower than that in the epidural space; and (c) whether threshold current in the epiradicular space overlaps with that in the epidural space or not.

\section{Materials and Methods}

After Institutional Review Board approval and informed written consent, 39 adult patients, with a history of low back pain and unilateral lumbosacral radiculopathy, were enrolled. All patients were situated in the prone position, and standard monitors were applied. The corresponding author who was supervising pain management fellows performed all injections. The patient was positioned with their back arched comfortably in the prone position. On the anteroposterior projection, with the image intensifier perpendicular to the patient, the lateral border of the contralateral pedicle of the supra-adjacent vertebra was identified as the entry point, and the skin and intended trajectory injected with $1 \%$ lidocaine. A 17-gauge Tuohy needle was inserted and angled directly caudomedially toward the junction of lamina and base of the spinous process. When bony contact was made, the tip of the needle was redirected caudally and advanced in the retrograde fashion until loss of resistance to normal saline solution was encountered.

A single port, metal coil-reinforced, 19-gauge epidural catheter containing a removable stylet (TheraCath; Arrow International, PA, USA) was inserted and $1 \mathrm{~cm}$ left in the posterior epidural space in 34 patients. The cathode lead of a constant current nerve stimulator (Braun Stimplex HNS 11; B Braun, PA, USA) was connected to the proximal end of stylet by use of a 2-headed alligator clip; the anode lead of the nerve stimulator was connected to an electrode placed on the patient's upper trunk skin as a ground site. The stimulating current was increased by increments of $0.1 \mathrm{~mA}$ from 0 to $5 \mathrm{~mA}$ (pulse width of $0.3 \mathrm{~ms}$; frequency of $2 \mathrm{~Hz}$ ) until palpable or visible unilateral or bilateral rhythmic muscle contractions were observed. Appropriate muscle contractions consisted of rhythmic hip adductors, iliopsoas, gluteus muscles, and hamstring group movement. Contraction of the muscle bed underneath the ground electrode was not considered appropriate. As our nerve stimulator was capable of delivering maximal current $5 \mathrm{~mA}$, if no twitches were present, the pulse width was changed to 1.0 ms and, again, the current incrementally increased from 0.1 to $5 \mathrm{~mA}$. Because the total number of charges (in nano-coulombs; $\mathrm{nC}$ ) delivered is equal to the product of the current (in milliAmperes; mA) and the pulse width (in milliseconds; ms) [17], 
the maximal number of charges delivered was, thus, $5 \mathrm{nC}$. The threshold current of motor response of the epidural space in milliAmpere unit (EDmA) was measured and converted into the nano-coulombs unit (EDnC) in accordance with the above formula. For our study, maximum threshold stimulation was considered to be the presence of muscle twitch at charges $\leq 5$ $\mathrm{nC}$.

With the completion of the epidural electrical stimulation, the catheter was advanced via the needle and passed in a retrograde fashion (toward the sacrum) to the lower aspect of contralateral pedicle in 34 patients. After approaching the lower aspect of contralateral pedicle, the catheter was advanced caudolaterally toward the target neural foramen until the catheter tip was located below the bisection of pedicle (Fig. 1). At this point, electrical stimulation of the epiradicular space was performed. The threshold current of motor response of the epiradicular space in milliAmpere unit (ERmA) was measured and converted into the nano-coulombs unit (ERnC). Recording of appropriate muscle contraction was done in the same manner mentioned above. The anteroposterior and lateral spot radiographs were obtained to confirm the position of the catheter. Epiradicular catheter placement was confirmed by fluoroscopic nerve root filling of contrast media. All epiradicular catheters were placed primarily for the control of lower extremity radiating pain and placed between L4-S1 segmental level.

Statistical significance between the EDnC and ERnC were analyzed by a one-sided paired $z$ test. As the standard deviation of the differences is known, the normal distribution was used instead of the $t$ distribution and the test is officially known as the

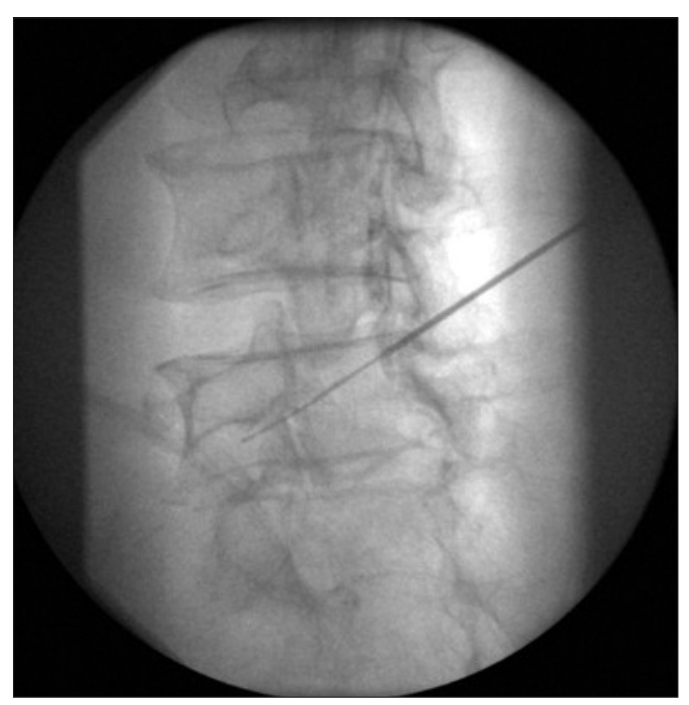

Fig. 1. Once placed at the epidural space, a 19-gauge radio-opaque spring-tipped epidural catheter with a wire stylet was passed, in a retrograde direction (toward the sacrum) into the epiradicular space below the pedicular bisection. $z$ test. Sample sizes of 12 achieve $95 \%$ power to detect a mean of paired difference of 1.6 with the known standard deviation of differences of 1.0. Differences were judged to be significant when $\mathrm{P}<0.05$

\section{Results}

Thirty-nine patients scheduled for epiradicular catheter placement agreed to take part in this study. Five patients were excluded: in 2 patients, epidural space could not be located; and in 3 patients, catheters were never advanced into the epiradicular space. Remaining 34 catheters were placed at the L4, L5, and S1 segmental level in 3, 29, and 2 cases, respectively. Table 1 shows patient demographic data. All catheters had an adequate loss of resistance to normal saline and uneventful epiradicular catheter insertion.

The distribution of EDnC and ERnC for 34 patients is shown in Fig. 2A. The EDnC and ERnC for 34 patients were $1.80 \pm 1.07$ $\mathrm{nC}$ (range: 0.26 to 4.21 ) and $0.18 \pm 0.20 \mathrm{nC}$ (range: 0.02 to 0.86 ), respectively. The ERnC was significantly lower than $\mathrm{EDnC}(\mathrm{P}<$ $0.05)$.

Of the 34 epidural catheters tested, the motor response was observed with the minimal current below $1 \mathrm{~mA}$ in 3 patients (Fig. 2B). Of the 31 patients with a motor response with current more than $1 \mathrm{~mA}, 9$ had responses at a current below $5 \mathrm{~mA}$ with a pulse width of $0.3 \mathrm{~ms}$, and 22 had motor response at a current between 1.5-5 mA with pulse width of $1.0 \mathrm{~ms}$. With the epidural stimulation, all patients with an appropriate muscle contraction had a unilateral motor response at the minimum current.

Of the 34 epiradicular catheters tested, the motor response was observed in 30 patients at an ERmA below $1 \mathrm{~mA}$. The ERmA for 34 patients was $0.59 \pm 0.66 \mathrm{~mA}$ (range: 0.06 to 2.84 ). As the EDmA and ERmA were below $1 \mathrm{~mA}$ in 3 patients and above $1 \mathrm{~mA}$ in 4 patients, respectively, it is suggested that threshold current of epiradicular space overlaps that in the epidural space at the lower limit current of $1 \mathrm{~mA}$. All 34 patients with

Table 1. Demographic Data

\begin{tabular}{lc}
\hline Patients (n) & 34 \\
Sex (M/F) & $25 / 9$ \\
Age (yr) & $55.6 \pm 13.6$ \\
Height (cm) & $159.0 \pm 9.2$ \\
Weight (kg) & $62.0 \pm 9.3$ \\
Laterality & \\
$\quad$ Right side (n) & 13 \\
$\quad$ Left side (n) & 21 \\
Pathology & \\
$\quad$ Disc herniation (n) & 14 \\
$\quad$ Spinal stenosis (n) & 20 \\
\hline
\end{tabular}

Data are expressed as number of patients, mean \pm SD. 
A

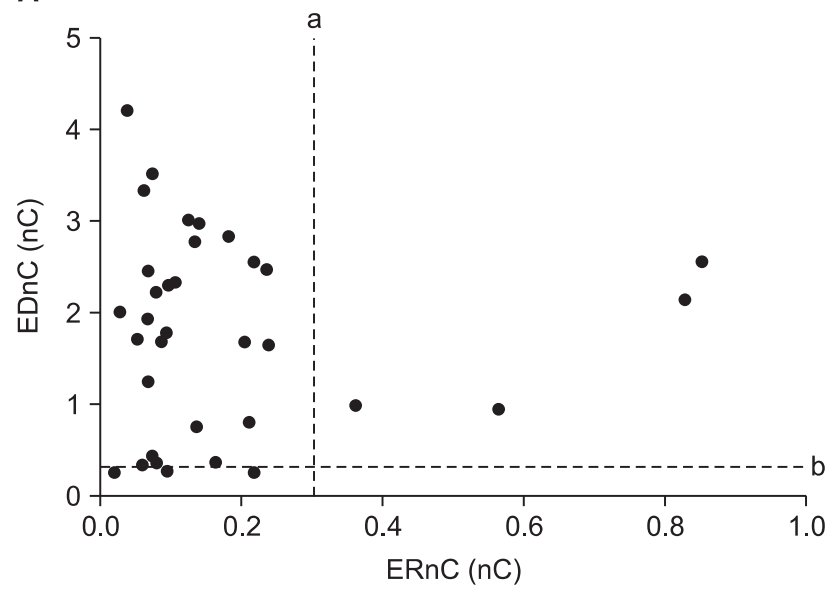

B

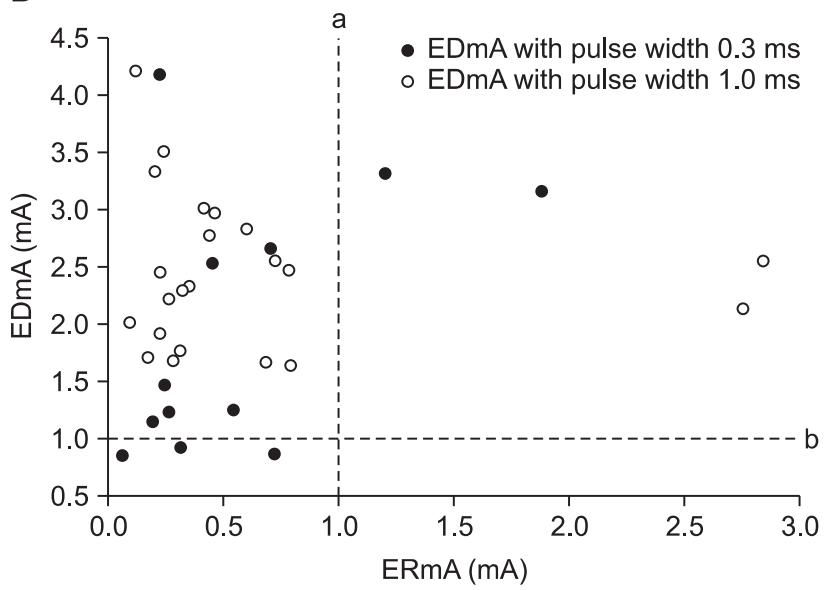

Fig. 2. Overlapping of threshold charges and current. (A) The distribution of threshold charges of the 34 patients is shown. (B) Scattergram showing the threshold current of the 34 patients. Both solid and vacant circles are ERmA for motor contraction with pulse width 0.3 ms. In regard to EDmA, solid circles are EDmA for motor contraction with pulse width $0.3 \mathrm{~ms}$, while vacant circles are EDmA with pulse width $1.0 \mathrm{~ms}$. Line $a$ and $b$ denote the threshold charges of $0.3 \mathrm{nC}$ in (A) or threshold current $1.0 \mathrm{~mA}$ with a pulse width of $0.3 \mathrm{~ms}$ in (B). ERnC/EDnC and $\mathrm{ERmA} / \mathrm{EDmA}$ are the threshold charges and current of motor response, respectively. ER and ED denote epiradicular and epidural, respectively.

an appropriate muscle contraction had satisfactory nerve root filling with injected contrast media. With the epiradicular stimulation, all patients with an appropriate muscle contraction had a unilateral motor response at the minimum current.

\section{Discussion}

The typical blind insertion of an epidural catheter into the epidural space risks catheter misplacement $[6,18]$. The EST is similar to using peripheral nerve stimulation to determine the catheter's vicinity to a peripheral motor nerve. The EST is designed not only to confirm the correct location of the epidural catheter, but also to suggest unintentional epidural catheter placement. In this study, the EST was performed as previously described [19] in the epiradicular space. The amount of electrical current applied, and whether an appropriate motor stimulation is generated, is thought to determine where the epidural catheter is located base on 2 parameters. First, studies have shown that appropriate muscle stimulation at a minimum current between 1 and $15 \mathrm{~mA}$ has a high positive predictive value of catheter being located in the epidural space $[15,20]$. Second, a motor response at a current $<1 \mathrm{~mA}$ revealed an intrathecal, subdural, or epiradicular placement of epidural catheter. In previous case reports [12-14], motor response occurs with: subdural catheter placement at $0.3 \mathrm{~mA}$ [13]; subarachnoid catheter placement at $0.4 \mathrm{~mA}$ [12]; and catheter tip placement in close proximity to nerve root at $0.5 \mathrm{~mA}$ [14].

The number of charges (in nano-coulombs; $\mathrm{nC}$ ) delivered is equal to the product of the current (in milliAmperes) and the pulse width (in milliseconds) [17]. In this study, the maximal number of charges delivered was, thus, $5.0 \mathrm{nC}(1.0 \mathrm{~ms} \times 5 \mathrm{~mA})$. In prior studies, the nerve stimulator was set at a pulse width of $0.2 \mathrm{~ms}$ with a frequency of $1 \mathrm{~Hz}[10,11,21]$. Our nerve stimulator was capable of delivering 0.3 and 1.0, but not $0.2 \mathrm{~ms}$, despite our ability to convey the same total number of charges as Tsui et al. $[10,14]$.

Our EDnC results of $1.80 \pm 1.07 \mathrm{nC}$ at a pulse width of 0.3 $\mathrm{ms}$ is equal to theoretical current of $9 \mathrm{~mA}$ at a pulse width of $0.2 \mathrm{~ms}$, because total charge level (in $\mathrm{nC}$ ) delivered is 1.80 $\mathrm{nC}(6 \mathrm{~mA} \times 0.3 \mathrm{~ms}$ or $9 \mathrm{~mA} \times 0.2 \mathrm{~ms})$. Charghi et al. [19] used an alternative mode of epidural stimulation as we had and epidural stimulation yielded a mean threshold of $1.90 \pm 1.80$ nC. Of 37 catheters intentionally placed in the epidural space, the mean current required to produce an appropriate palpable motor contraction was $7.8 \mathrm{~mA}$ [22]. Our results of a $1.8 \mathrm{nC}$ or theoretical current of $9 \mathrm{~mA}$ is comparable to that of a prior study [22]. In addition, our ERmA results of $0.59 \pm 0.66 \mathrm{~mA}$ at a pulse width $0.3 \mathrm{~ms}$ is equal to theoretical current $0.8 \mathrm{~mA}$ at a pulse width $0.2 \mathrm{~ms}$, because total charge level (in $\mathrm{nC}$ ) delivered is 0.16 $\mathrm{nC}(0.59 \mathrm{~mA} \times 0.3 \mathrm{~ms}$ or $0.8 \mathrm{~mA} \times 0.2 \mathrm{~ms})$. Tsui et al. [14], used a catheter of which the tip was found to be lying near a nerve root and primed with normal saline, and a pulse width of 0.2 $\mathrm{ms}$ have reported a motor response occurring at $0.5 \mathrm{~mA}$. Our results mirror these findings, our epiradicular catheters were able to elicit a motor response at the theoretical current of 0.8 $\mathrm{mA}$. We must emphasize, however, that extreme caution must be exercised when comparing our data with results previously obtained that employed the technique of Tsui et al. [21,23]. Because of the different pulse width used, our data may not be directly comparable with previous studies [10,14-16,22]. 
Limitation of this study is that threshold currents were not directly compared between epiradicular and epidural placement. The upper limit of epidural stimulation requirement is over $15 \mathrm{~mA}$ [15]. As our nerve stimulator was capable of delivering maximal current $5 \mathrm{~mA}$ with a pulse width $0.3 \mathrm{~ms}$, observation of threshold current of motor response above $5 \mathrm{~mA}$ for epidural catheter placement was not feasible. In this study, if no twitches were present, the pulse width was changed to 1.0 $\mathrm{ms}$ and, again, the current incrementally increased from 0.1 to 5 $\mathrm{mA}$. We were not able to directly compare the epiradicular and epidural threshold current, because pulse width was changed if no twitches were present. Instead of the threshold current, we compared the threshold charge. In this study, the ERnC $(0.18 \pm$ $0.20 \mathrm{nC})$ was significantly lower than EDnC $(1.80 \pm 1.07 \mathrm{nC})$. The observational results of our study correlate with prior literature in that the mean threshold current was lower for epiradicular (theoretical current $0.8 \mathrm{~mA}$ in this study) compared with epidural catheter $[15,16,22]$ placement.

The minimum current requirements for appropriate motor stimulation of catheters placed in the epidural and intrathecal spaces were evaluated clinically [22] and in porcine model [9]. Despite that the minimum electrical current requirement seems to be lower for intrathecal compared with epidural catheter placement, the threshold current required in the intrathecal space in order to elicit a motor response overlaps with the epidural space in clinical studies, [22] but not from animal studies [9]. Likewise, we observed the epiradicular threshold current (or charges) overlapping the epidural threshold current (or charges) (Fig. 2). In our study, such unilateral segmental responses at $>1 \mathrm{~mA}$ were encountered during epiradicular stimulation. At the right of dotted line, a in Fig. 2B, ERmA was observed above $1 \mathrm{~mA}$ in 4 patients. Of the 4 patients, 2 had a motor response at currents above $2 \mathrm{~mA}$ and 2 patients had a response at a current between $1-2 \mathrm{~mA}$. The mean threshold current for the 4 patients was $2.17 \pm 0.78 \mathrm{~mA}$, which are in accordance with the threshold current in the epidural space $[10,11]$, although adequate location of epiradicular catheter could be confirmed by adequate nerve root filling with contrast media injection. In contrast to the ERmA above $1 \mathrm{~mA}$, the EDmA of 3 patients were below $1 \mathrm{~mA}$ (below the dotted line $\mathrm{b}$ in Fig. 2B). The EDmA for these 3 patients were $0.90 \pm 0.04 \mathrm{~mA}$ (range: 0.87 to 0.94 ). Actually, de Medicis et al. [15] applied different EST criteria to verify the location of epidural catheter especially regarding the lower limit current $1 \mathrm{~mA}$. de Medicis et al. [15] applied modified criteria that is different from that of Tsui's criteria [11]; a segmental unilateral motor response $<1 \mathrm{~mA}$ or a segmental response (unilateral or bilateral) $1-10$ $\mathrm{mA}$ was considered positive for adequate epidural space catheterization. Of the 167 patients with a positive epidural stimulation test, 9 had unilateral motor response with a current less than or equal to $1 \mathrm{~mA}$, even though the adequate location of epidural catheter was confirmed [15]. Furthermore Foster et al. [16] observed unilateral, segmental motor responses at $<1$ $\mathrm{mA}$ in 2 of the 25 patients with epidural stimulation. Our results mirror these findings, as our epidural catheters were able to elicit motor response at $0.90 \pm 0.04 \mathrm{~mA}$ (range: 0.87 to 0.94 ) in 3 patients with the motor response observed with the minimal current below $1 \mathrm{~mA}$.

In this study, EDmA and ERmA were below $1 \mathrm{~mA}$ in 3 patients and above $1 \mathrm{~mA}$ in 4 patients (Fig. 2B). This means overlapping of epidural threshold current with that of epiradicular space. As highlighted before [11], the lower cutoff $<1 \mathrm{~mA}$ should not be considered an absolute limit, but always a warning sign for possible epiradicular, subdural, or subarachnoid position $[9,10,12,24,25]$. The data from our patients with epiradicular catheter placement are in line with this concept.

The electrical stimulation test performance results must be interpreted cautiously because of the specific patients group enrolled. In this study, epiradicular catheters were inserted for patients complaining of low extremity radiating pain due to spinal pathology. In our small case series, diversity of pathophysiology might have influence the results of epidural and epiradicular current threshold. A unilateral response was observed at a low epidural current $(0.90 \pm 0.04 \mathrm{~mA}$; range: 0.87 to 0.94 ) in 3 patients. We hypothesized that the typical characteristic of an epidural catheter close to a nerve root is unilateral motor response with very low current (i.e., $<1$ $\mathrm{mA}$ ) and epidural threshold current $<1 \mathrm{~mA}$ could be partially explained by the catheter tip localization adjacent to the nerve root owing to reduced central spinal canal area. On the other hand, following nerve root trauma, axonal changes indicative of dysfunction and degeneration develop, which depend on the specific mechanical input of tissue loading [26,27]. Nerve root compression produced endoneural edema, membrane leakage, and Wallerian degeneration $[28,29]$. Nerve root compression and degeneration could be caused with lateral spinal stenosis, subarticular entrapment, and foraminal stenosis. We hypothesized that epiradicular current threshold might be increased (ie, $>1 \mathrm{~mA}$ ) with the catheter tip localized to the degenerated nerve root. It cannot exclude our observation of epiradicular current threshold $>1 \mathrm{~mA}$, which was found in 4 patients. The overlapping of the threshold current might be explained by location of the catheter tip adjacent to the nerve root and chronic compression resulting in microvascular injury. However, we have evaluated the threshold current of the specific patients group with spinal pathology and it is difficult to extrapolate the results from this study to the patients without spinal pathology.

Most of the threshold current used in Tsui's criteria were 
derived by practical applications of ease of memory and technical use [11]. That is, based on a series of assumptions, criteria for the localization of catheter are derived. Unfortunately, the criteria are only as realistic as the assumptions upon which it is based. If the assumptions are inaccurate in a certain situation, the criteria may be inaccurate, as well. Tsui et al. should be commended for the statement in his original article, "the absolute numerical value of lower limit $1 \mathrm{~mA}$ settings are intended as guideline and may require adjustment as experience increases" [10].

The insulated epidural catheter we used in our study was different from that of prior EST studies. As the effective conduction of electricity is essential for the success of the EST, the type of catheter is important. The most common method of epidural stimulation, described by Tsui et al. [10], relies on the use of a catheter (Arrow Flex Tip Plus; Arrow International, PA, USA) connected to a nerve stimulator via a special adaptor (Johans ECG Adaptor; Arrow International, PA, USA). We used an alternative mode of epidural stimulation with a single-port, metal coil-reinforced catheter containing a removable stylet (TheraCath; Arrow International, PA, USA). However, it was demonstrated that TheraCath (the catheter that we chose) provided effective electrostimulation of the epidural space and offered an alternative to the traditional method of using a catheter primed with normal saline [19].

It was demonstrated that short duration stimuli are more precise in predicting the needle-nerve relationship [30]. In electrophysiologic terms, despite an equal total number of charges delivered, triggering of an action potential requires all charges to be delivered within a short period of time. Thus, stimulation of motor fibers may be easier at 0.2 than 0.3 or 1.0 $\mathrm{ms}$, because $0.2 \mathrm{~ms}$ is closer to the motor fiber's chronaxie [19]. In prior studies, the nerve stimulator was set at a pulse width of $0.2 \mathrm{~ms}$ with a frequency of $1 \mathrm{~Hz}[10,11,21]$, considering the chronaxie. Another difference in our study compared with prior EST studies involves the setting of a pulse width. In this study, the stimulator was set at a pulse width of $0.3 \mathrm{~ms}$ with a frequency of $2 \mathrm{~Hz}$. It is possible that variations in stimulus duration may affect patient comfort, as well as the success of epidural stimulation, however the clinical effects were unknown.

In conclusion, we found that the threshold current for motor response seems to be lower for epiradicular compared with epidural placement, although we were not able to directly investigate the epidural threshold current. Results from this investigation, support the hypothesis of the Tsui's test that there is a significant difference in the threshold current required to elicit a motor response with an insulated needle between the epiradicular and epidural space. In addition, the threshold current of epiradicular space overlaps that of the epidural space. Threshold current of epiradicular space overlap that in the epidural space at the lower limit current of $1 \mathrm{~mA}$, because motor response with threshold current adjacent to $1 \mathrm{~mA}$ include epiradicular or epidural catheter placement. Further studies will be needed to determine the role of epiradicular stimulation in monitoring epiradicular needle advancement and preventing unintended epiradicular block.

\section{References}

1. Dolin SJ, Cashman JN, Bland JM. Effectiveness of acute postoperative pain management: I. Evidence from published data. $\mathrm{Br} \mathrm{J}$ Anaesth 2002; 89: 409-23.

2. Block BM, Liu SS, Rowlingson AJ, Cowan AR, Cowan JA Jr, Wu CL. Efficacy of postoperative epidural analgesia: a meta-analysis. JAMA 2003; 290: 2455-63.

3. Werawatganon T, Charuluxanun S. Patient controlled intravenous opioid analgesia versus continuous epidural analgesia for pain after intra-abdominal surgery. Cochrane Database Syst Rev 2005; 25 : CD004088.

4. Nishimori M, Ballantyne JC, Low JH. Epidural pain relief versus systemic opioid-based pain relief for abdominal aortic surgery. Cochrane Database Syst Rev 2006; 19: CD005059.

5. Rigg JR, Jamrozik K, Myles PS, Silbert BS, Peyton PJ, Parsons RW, et al. Epidural anaesthesia and analgesia and outcome of major surgery: a randomised trial. Lancet 2002; 359: 1276-82.

6. Asato F, Goto F. Radiographic findings of unilateral epidural block. Anesth Analg 1996; 83: 519-22.

7. Bromage PR, Benumof JL. Paraplegia following intracord injection during attempted epidural anesthesia under general anesthesia. Reg Anesth Pain Med 1998; 23: 104-7.

8. Kasai T, Yaegashi K, Hirose M, Tanaka Y. Spinal cord injury in a child caused by an accidental dural puncture with a single-shot thoracic epidural needle. Anesth Analg 2003; 96: 65-7.

9. Tsui BC, Wagner A, Finucane B. The threshold current in the intrathecal space to elicit motor response is lower and does not overlap that in the epidural space: a porcine model. Can J Anaesth 2004; 51: 690-5.

10. Tsui BC, Gupta S, Finucane B. Confirmation of epidural catheter placement using nerve stimulation. Can J Anaesth 1998; 45: 640-4.

11. Tsui BC. Epidural stimulation test criteria. Anesth Analg 2006; 103: 775-6.

12. Tsui BC, Gupta S, Finucane B. Detection of subarachnoid and intravascular epidural catheter placement. Can J Anaesth 1999; 46: 6758.

13. Tsui BC, Gupta S, Emery D, Finucane B. Detection of subdural placement of epidural catheter using nerve stimulation. Can J Anaesth 2000; 47: 471-3.

14. Tsui BC, Guenther C, Emery D, Finucane B. Determining epidural catheter location using nerve stimulation with radiological confirmation. Reg Anesth Pain Med 2000; 25: 306-9.

15. de Medicis E, Tetrault JP, Martin R, Robichaud R, Laroche L. A prospective comparative study of two indirect methods for confirming the localization of an epidural catheter for postoperative analgesia. Anesth Analg 2005; 101: 1830-3. 
16. Forster JG, Niemi TT, Salmenpera MT, Ikonen S, Rosenberg PH. An evaluation of the epidural catheter position by epidural nerve stimulation in conjunction with continuous epidural analgesia in adult surgical patients. Anesth Analg 2009; 108: 351-8.

17. Hadzic A, Vloka J, Hadzic N, Thys DM, Santos AC. Nerve stimulators used for peripheral nerve blocks vary in their electrical characteristics. Anesthesiology 2003; 98: 969-74.

18. Richardson MG, Lee AC, Wissler RN. High spinal anesthesia after epidural test dose administration in five obstetric patients. Reg Anesth 1996; 21: 119-23.

19. Charghi R, Chan SY, Kardash KJ, Finlayson RJ, Tran de QH. Electrical stimulation of the epidural space using a catheter with a removable stylet. Reg Anesth Pain Med 2007; 32: 152-6.

20. Goobie SM, Montgomery CJ, Basu R, McFadzean J, O'Connor GJ, Poskitt K, et al. Confirmation of direct epidural catheter placement using nerve stimulation in pediatric anesthesia. Anesth Analg 2003; 97: 984-8.

21. Tsui BC, Gupta S, Finucane B. Determination of epidural catheter placement using nerve stimulation in obstetric patients. Reg Anesth Pain Med 1999; 24: 17-23.

22. Sutherland MA, Viscomi CM, Dominick TS, Anderson EL. Minimum current requirements for epidural stimulation test confirmation of epidural and intrathecal catheter placement. Reg Anesth Pain Med 2009; 34: 575-7.
23. Tsui BC, Tarkkila P, Gupta S, Kearney R. Confirmation of caudal needle placement using nerve stimulation. Anesthesiology 1999; 91: 374-8.

24. Tsui BC, Wagner AM, Cunningham K, Perry S, Desai S, Seal R. Threshold current of an insulated needle in the intrathecal space in pediatric patients. Anesth Analg 2005; 100: 662-5.

25. Lena P, Martin R. Subdural placement of an epidural catheter detected by nerve stimulation. Can J Anaesth 2005; 52: 618-21.

26. Singh A, Lu Y, Chen C, Kallakuri S, Cavanaugh JM. A new model of traumatic axonal injury to determine the effects of strain and displacement rates. Stapp Car Crash J 2006; 50: 601-23.

27. Chung RS, Staal JA, McCormack GH, Dickson TC, Cozens MA, Chuckowree JA, et al. Mild axonal stretch injury in vitro induces a progressive series of neurofilament alterations ultimately leading to delayed axotomy. J Neurotrauma 2005; 22: 1081-91.

28. Sekiguchi M, Kikuchi S, Myers RR. Experimental spinal stenosis: relationship between degree of cauda equina compression, neuropathology, and pain. Spine (Phila Pa 1976) 2004; 29: 1105-11.

29. Kobayashi S, Yoshizawa H. Effect of mechanical compression on the vascular permeability of the dorsal root ganglion. J Orthop Res 2002; 20: 730-9.

30. Ford DJ, Pither C, Raj PP. Comparison of insulated and uninsulated needles for locating peripheral nerves with a peripheral nerve stimulator. Anesth Analg 1984; 63: 925-8. 